\title{
A FUNÇÃO SOCIAL DA PROPRIEDADE RURAL E A RESERVA LEGAL NA AMAZÔNIA
}

Luciana Costa da Fonseca ${ }^{1}$

Centro Universitário do Pará (CESUPA)

\section{RESUMO}

A pesquisa investiga qual a relação jurídica entre a Reserva Legal e o princípio da função social da propriedade na Amazônia. O objetivo geral é contribuir para a aplicação da Reserva Legal como instrumento de efetivação da função social da propriedade na Amazônia. A pesquisa analisa o conteúdo jurídico do direito fundamental à propriedade e da função social da propriedade, a evolução da regulamentação da Reserva Legal, desde seu surgimento até o momento atual, e a aplicação do redimensionamento da Reserva Legal no estado do Pará, visando compreender a relação entre a Reserva Legal e a função social da propriedade. A metodologia utilizada envolveu o método dedutivo, abordagem qualitativa e técnica de pesquisa bibliográfica e documental. A pesquisa concluiu que a função social da propriedade é o fundamento jurídico para o instituto da Reserva Legal; por outro lado, esta passou a ser uma das condições de cumprimento do aspecto ambiental da função social da propriedade. O cumprimento da Reserva Legal pelo proprietário do imóvel deixa de ser exclusivamente um direito-garantia do proprietário e se torna um direito-garantia da sociedade de conservação do bioma Amazônia.

Palavras-chave: Amazônia; função social da propriedade; Reserva Legal.

1 Doutorado em Direitos Difusos e Coletivos pela Pontifícia Universidade Católica de São Paulo (PUC-SP). Mestrado em Direitos Difusos e Coletivos pela PUC-SP). Especialista em Direito Sanitário pela Universidade de São Paulo (USP). Professora adjunta da Universidade Federal do Pará (UFPA). Professora da Graduação e Pós-Graduação do CESUPA. ORCID: https://orcid.org/0000-0002-32108943 / e-mail: lucianacfonseca@uol.com.br 


\section{THE SOCIAL FUNCTION OF RURAL PROPERTY AND THE LEGAL RESERVE IN THE AMAZON}

\section{ABSTRACT}

This research investigates the legal relationship between the Legal Reserve and the social function of property in the Amazon. The general objective of the research is to contribute with the application of the Legal Reserve as an instrument of the social function in Amazon. The research analyzes the legal content of the right to property and the social function of property; the evolution of Legal Reserve regulation, from its inception until the present moment, and the application of the Legal Reserve resizing in the State of Pará, aiming to understand the relationship between the Legal Reserve and the social function of property. The methodology used involved the deductive method, qualitative approach and documentary bibliographic research technique. The research shows that the Legal Reserve is determinant for the analysis of the environmental aspect of the social function of the property in Amazon. On the one hand the social function of property is the foundation for the creation of the Legal Reserve, on the other it becomes one of the conditions for compliance with the environmental aspect of social function of property. The social function of property ceases to be exclusively a right-guarantee of the owner and becomes a right-guarantee of society to the conservation of the Amazon biome.

Keywords: Amazon; legal reserve; social function of rural property. 


\section{INTRODUÇÃO}

$\mathrm{O}$ adequado exercício do direito fundamental à propriedade privada é determinante para a proteção das áreas de florestas e o enfretamento do desafio socioambiental na Amazônia. As políticas públicas na região têm sido desenvolvidas com fundamento em uma produção legislativa vasta, esparsa e confusa, com grande impacto para o exercício da propriedade privada e para o uso e ocupação do solo.

A propriedade privada e a função social da propriedade são direitos fundamentais e princípio da ordem econômica, previstos na Constituição da República Federativa do Brasil - CRFB (BRASIL, 1988) e devem ser exercidos de forma compatível com os demais direitos fundamentais individuais, sociais e difusos, como o direito ao meio ambiente ecologicamente equilibrado.

A função social da propriedade fundamenta institutos de proteção ambiental como a Reserva Legal, prevista na Lei Federal n. 12.651/2012 (BRASIL, 2012), popularmente conhecida como Novo Código Florestal, que compreende que uma área localizada no interior de uma propriedade ou posse rural deve ser conservada com cobertura de vegetação nativa, visando assegurar o uso econômico de modo sustentável dos recursos naturais do imóvel rural, auxiliar a conservação e a reabilitação dos processos ecológicos e promover a conservação da biodiversidade, a proteção de fauna silvestre e da flora nativa.

A Reserva Legal impõe uma restrição ao uso do solo na Amazônia, vedando a possibilidade de corte raso na área de floresta, que pode alcançar $80 \%$ da área do imóvel. A restrição pode ser relativizada por meio das hipóteses de redimensionamento previstas no Código Florestal, que merecem estudo cuidadoso diante da diversidade de interpretações possíveis.

O problema de pesquisa investiga qual a relação jurídica entre a Reserva Legal e o princípio da função social da propriedade na Amazônia. O objetivo geral da pesquisa é contribuir para adequada aplicação da Reserva Legal como instrumento de efetivação da função social da propriedade na Amazônia.

A pesquisa tem como objetivos específicos: (i) analisar o conteúdo jurídico do direito fundamental à propriedade e da função social da propriedade, envolvendo o estudo das teorias de direito fundamental e da relação jurídica entre propriedade privada e sua função social; (ii) identificar a evolução legislativa da Reserva Legal, desde seu surgimento 
até o momento atual, no âmbito da legislação federal e da legislação estadual do Pará, buscando demonstrar como a intensa alteração legislativa dificulta a compreensão e aplicação do instituto; e (iii) compreender qual a natureza da relação entre a Reserva Legal e a função social da propriedade.

Atualmente a Amazônia Legal é formada por todos os estados da região Norte do Brasil (Acre, Amazonas, Amapá, Pará, Rondônia, Roraima e Tocantins), toda a área de Mato Grosso e parte do estado do Maranhão, porém a pesquisa analisa especificamente as dificuldades de regulamentação da Reserva Legal no estado do Pará e utilizou como critério de escolha a situação do estado como líder nas taxas de desmatamento anual na Amazônia no último ano de 2018 (INPE, 2019).

A metodologia utilizada envolveu o método dedutivo, abordagem qualitativa e técnica de pesquisa bibliográfica e documental, cujo objetivo foi explicar o conteúdo das premissas por meio do raciocínio em ordem descendente, partindo da análise do conceito geral para o particular, até chegar à conclusão (PRODANOV; FREITAS, 2013).

\section{O CONTEÚDO JURÍDICO DA PROPRIEDADE PRIVADA E DA FUNÇÃO SOCIAL DA PROPRIEDADE RURAL}

A propriedade privada é um dos temas mais preciosos para o sistema capitalista de produção, que passou por intensa expansão global da economia, marcada pela flexibilização dos direitos sociais e inovações tecnológicas. É evidente que a propriedade privada também passou por intensa transformação decorrente das diversas formas de manifestação do capitalismo em constante transformação.

A pesquisa parte do estudo do atual conteúdo jurídico da propriedade privada no Brasil, para enfrentar o debate jurídico sobre a noção de função social da propriedade.

A expressão propriedade privada é utilizada para designar diferentes relações e bens no sistema jurídico brasileiro. A Constituição (BRASIL, 1988) dispõe sobre a propriedade de diversos sentidos: (a) propriedade como direito à proteção da relação jurídica de propriedade (art. $5^{\circ}$, caput, e inc. XXII); (b) propriedade e a função social da propriedade como princípios jurídicos (art. 170, II, III); (c) propriedade como bem (art. 5, XIII, XXV, XXVI, arts. 182 e 186).

Evidentemente a diversidade de sentido da expressão dificulta a compreensão de seu conteúdo jurídico. Eros Grau (1983, p. 64) conclui 
que "a propriedade, por certo, não constitui uma instituição única, mas sim um conjunto de várias instituições distintas, relacionadas a diversos tipos de bens".

O art. $5^{\circ}$, caput, e inc. XXII da Constituição (BRASIL, 1988) dispõe sobre os direitos e deveres individuais e coletivos e garante aos brasileiros e aos estrangeiros residentes no país a inviolabilidade do direito à propriedade. A propriedade é garantida desta forma, o que indica uma relação entre um indivíduo e um objeto e também indica uma oposição entre o sujeito dessa relação e a universalidade de sujeitos que também poderiam pretender participar da relação, mas que estão excluídos em razão dos fundamentos do direito (FIGUEIREDO, 2008).

Sobre o direito à proteção da relação jurídica de propriedade, é necessário fazer a ressalva bem esclarecida por Derani (2002, p. 58):

\footnotetext{
Propriedade traduz uma relação, sobre a qual recai uma proteção jurídica. Não é a propriedade um direito. Direito é sua proteção. Assim direito de propriedade é o direito à proteção da relação de um sujeito sobre um objeto. Somente aquela relação que preenche requisitos determinados pelo direito é passível de ser protegida.
}

Cristiane Derani (2002) alerta que a doutrina brasileira e a própria Constituição usam a expressão propriedade de forma ambígua, empregando ora como para designar uma relação entre o sujeito e o objeto, ora para determinar o objeto da relação.

\subsection{Propriedade e a função social da propriedade como princípios jurídicos}

O art. 170 da Constituição (BRASIL, 1988) dispõe que a ordem econômica, fundada na valorização do trabalho humano e na livre iniciativa, tem por fim assegurar a todos uma existência digna, conforme os ditames da justiça social, e elege como princípios da ordem econômica a propriedade e a função social da propriedade (BRASIL, 1988, art. 170, I, II).

Assim,énecessárioanalisararelevânciadosprincípios parainterpretação e aplicação das normas jurídicas. A interpretação constitucional adotada na pesquisa tem como fundamento o sistema jurídico como o conjunto de princípios e regras, conforme modelo proposto por Robert Alexy (2002), no qual os princípios são normas que ordenam que algo seja realizado na maior medida possível, dentro das possibilidades jurídicas e fáticas existentes, sendo, portanto, mandados de optimização, caracterizados 
pelo fato de que podem ser cumpridos em diferentes graus. A medida de seu cumprimento depende das referidas possibilidades fáticas e jurídicas existentes. As regras, ao contrário, só podem ser cumpridas ou não. $\mathrm{O}$ conflito de regras só pode ser solucionado introduzindo em uma das regras uma cláusula de exceção que elimina o conflito, ou declarando inválida, ao menos, uma das regras. Quando ocorre a colisão entre princípios, um deles deve ceder diante do outro. Porém, isso não significa que o princípio desprezado seja considerado inválido, nem que seja necessário introduzir uma cláusula de exceção, pois em certas circunstâncias, um dos princípios precede ao outro.

O sistema jurídico baseado em princípios fundamenta-se em valores e permite a avaliação dos aspectos circunstanciais no momento da aplicação do Direito, servindo como vetor de interpretação das regras jurídicas produzidas no âmbito infraconstitucional, quando o intérprete poderá escolher a possibilidade mais adequada para o alcance dos objetivos sociais, dentre todas as possibilidades. Eros Grau alerta que não existe norma ou instituto jurídico que não deva sua origem a uma finalidade, daí a importância das normas-objetivo (GRAU, 2005). Os princípios constitucionais devem buscar a concretização dos objetivos da República, eleitos no art. $3^{\circ}$ da Constituição (BRASIL, 1988).

O art. 170 da Constituição (BRASIL, 1988) dispõe que a propriedade privada são princípios da ordem econômica e, portanto, devem ser cumpridos na maior medida possível. Especificamente sobre a propriedade rural, o art. 186 da Constituição (BRASIL, 1988) determina que a função social é cumprida quando a propriedade rural atende requisitos econômicos, sociais e ambientais assim especificados: aproveitamento racional e adequado; utilização adequada dos recursos naturais e preservação do meio ambiente; observância das disposições que regulam as relações de trabalho e exploração que favoreça o bem-estar dos proprietários e dos trabalhadores.

O critério do uso racional da propriedade sempre foi exigência para exploração da terra, desde as concessões por meio de sesmaria, feitas pela Coroa Portuguesa, e posteriormente, a legislação brasileira manteve a exigência de cultura efetiva para reconhecimento da posse e acesso à terra, desde a Lei n. 601, de 1850, Lei de Terras até hoje (ROCHA et al., 2015).

O critério ambiental foi se tornando relevante com a intensificação da crise ambiental no Brasil e no mundo e certamente é um dos grandes desafios da noção da função social da propriedade porque exige que a terra 
seja utilizada de forma racional para garantir sua produtividade, porém, também exige que seja utilizada de forma sustentável para garantir a preservação da biodiversidade.

O art. 225 da Constituição (BRASIL, 1988) preenche o conteúdo da função ambiental da propriedade privada quando determina que todos têm direito a um meio ambiente ecologicamente equilibrado, essencial para qualidade de vida sadia, incumbido ao Poder Público e à coletividade o dever de defesa e preservação. $\mathrm{O} \S 1^{\circ}$ do art. 225 estabelece deveres específicos destinados ao Poder Público que impactam o exercício da propriedade privada: dever de preservar e restaurar os processos ecológicos essenciais e prover o manejo ecológico das espécies e ecossistemas, exigir estudo prévio de impactos para instalação de obra ou atividade potencialmente causadora de significativa degradação do meio ambiente, proteger a fauna e a flora, vedadas, na forma da lei, as práticas que coloquem em risco sua função ecológica, provoquem a extinção de espécies ou submetam os animais a crueldade.

Deve-se observar que o imóvel rural que não esteja cumprindo sua função social está suscetível a desapropriação para fins de reforma agrária, mediante prévia e justa indenização em títulos da dívida agrária, com cláusula de preservação do valor real, resgatável no prazo de até vinte anos a partir do segundo ano de sua emissão, conforme o art. 184 da Constituição (BRASIL, 1988), porém não há regulamentação dos critérios para a definição do descumprimento das exigências ambientais que justificariam a desapropriação.

Especificamente sobre a propriedade urbana, o art. $182, \S 2^{\circ}$, da Constituição (BRASIL, 1988) dispõe que a propriedade urbana cumpre sua função social quando atende às exigências fundamentais de ordenação da cidade expressas no plano diretor.

\subsection{A relação entre a propriedade privada e a função social da propriedade}

A propriedade privada e a função social da propriedade são direitos fundamentais e deve sem ser analisados considerando essa teoria.

Perez Luno (2005) ressalta a dupla função dos direitos fundamentais: no plano subjetivo, atuam como garantia da liberdade individual e no plano objetivo, assumiram uma dimensão institucional, a partir da qual seu conteúdo deve funcionalizar-se para consecução dos fins e valores constitucionalmente proclamados. 
Os direitos fundamentais assumiram uma importância vital para o constitucionalismo. Como afirma Perez Luno (2005), há uma estreita relação de interdependência genética e funcional entre estado de direito e os direitos fundamentais, uma vez que o estado de direito exige e implica a garantia dos direitos fundamentais, e estes implicam a existência de um estado de direito para sua realização.

O tema dos direitos humanos remete à polêmica acerca de seus fundamentos, que não será tratada no texto, mas destaca-se a lição de Norberto Bobbio (1992) sobre a chamada crise dos fundamentos, no sentido de que não mais se permite a ilusão do fundamento absoluto, preconizada pelos jusnaturalistas.

Duas teorias acerca dos direitos fundamentais merecem destaque na doutrina: a teoria da evolução, segundo o sistema de gerações de direitos, e a teoria da indivisibilidade dos direitos humanos. O sistema de gerações parte da constatação da história da humanidade para identificar a afirmação dos direitos fundamentais em função da ocorrência de eventos ou manifestações de opressão não tolerados pela civilização atingida, segundo seus valores culturais em determinado momento histórico. A partir dessa observação, a teoria dos direitos fundamentais os concentra em gerações distintas, utilizando como critério a característica comum aos direitos conquistados em relação ao momento histórico vivido (BOBBIO, 1992).

A doutrina que se formou em torno dos direitos humanos reconhece que não há uma superação no aparecimento e positivação dos direitos humanos, não há uma ruptura em relação às conquistas antecedentes, mas uma ampliação ou complementaridade de direitos na passagem de uma geração a outra. Por essa razão, parte da doutrina propõe a substituição da expressão gerações por dimensões de direitos fundamentais. Para Bonavides (2005), o vocábulo dimensão substitui, com vantagem lógica e qualitativa, o termo geração, caso este último venha a induzir apenas sucessão cronológica e, portanto, suposta caducidade dos direitos das gerações antecedentes.

A teoria da indivisibilidade dos direitos humanos propõe outra perspectiva na relação entre os direitos fundamentais, negando a divisão clássica entre direitos civis e políticos e os direitos econômicos, sociais e culturais, sob a argumentação de que os direitos fundamentais são indivisíveis. Os direitos civis e políticos não podem ser concretizados sem os direitos econômicos, sociais, culturais e vice-versa. A maior contribuição da teoria da indivisibilidade é repelir a distinção entre os direitos civis e políticos e os direitos socais, e questionar a aplicabilidade imediata dos 
primeiros, em contraposição à aplicabilidade progressiva dos últimos (LIMA JR., 2001).

Outro importante aspecto a ser tratado é a possibilidade de restrição dos direitos fundamentais. A teoria dos direitos fundamentais tem o entendimento de que que tais direitos não são absolutos. Determinar o conceito de restrição aos direitos fundamentais é um dos mais complexos desafios da doutrina. As mais prestigiadas teorias sobre as restrições de direitos fundamentais são as teorias interna e externa.

Alexy (2002) explica que, para a teoria externa, o conceito de restrição a um direito indica a existência do direito e sua restrição. Logo, há em primeiro lugar o direito em si, não restringido e em segundo lugar, aquilo que resta após a ocorrência de uma restrição, o direito restringido. Assim, os direitos apresentam-se como direitos restringidos, mas também concebíveis sem restrições.

Diferentemente, para a teoria interna não existem duas coisas, o direito e sua restrição, mas apenas o direito com determinado conteúdo. O conceito de restrição é substituído pelo conceito de limite. Alexy (2002) ressalta que as dúvidas acerca dos limites do direito não são dúvidas sobre quão extensa pode ser sua restrição, mas dúvidas sobre seu conteúdo.

$\mathrm{Na}$ teoria interna há um sistema de equilíbrio e um condicionamento recíproco entre os bens jurídicos constitucionais, exigindo a interpretação do texto constitucional como um todo. Os direitos fundamentais estariam limitados pela unidade da Constituição.

O conteúdo acerca da proteção jurídica da propriedade privada deve ser analisado em conjunto com o conteúdo da função social da propriedade, que também passou por intensas transformações desde a filosofia de Augusto Comte, passando pela doutrina social da Igreja Católica Romana, pelo Constitucionalismo de Weimar e pelo Socialismo (FIGUEIREDO, 2008).

Grau (1983) afirma que a propriedade enquanto função social é um princípio que integra o conceito de positivismo jurídico sobre a propriedade, determinando profundas alterações estruturais, por esta razão se transforma em um dever e não é o objeto de propriedade que tem a função, e sim o titular da propriedade. Ou seja, quem cumpre a função embutida na propriedade de que é titular é o proprietário do objeto.

Diferentemente de Grau, Cristiane Derani (2002) afirma a função social não como função de um direito, nem de um bem inanimado ou do titular da propriedade, como afirma Grau, mas sim a vinculação dos efeitos 
da relação sujeito-objeto com a sociedade. A propriedade é o direito à proteção da relação de um sujeito sobre um objeto. Assim, a função social cria um ônus do proprietário privado perante a sociedade, que recai sobre o desenvolvimento da relação de poder entre sujeito e objeto, e é esta relação que configura a propriedade. O ônus significa que sua atuação deve trazer um resultado vantajoso para a sociedade como consequência jurídica para garantia do direito, conforme Derani (2002, p. 62):

Em consequência, da mesma forma que é conferido um direito subjetivo individual para o proprietário reclamar a garantia da relação de propriedade, é atribuído ao Estado e à coletividade o direito subjetivo público para exigir do sujeito proprietário a realização de determinadas ações, a fim de que a relação de propriedade mantenha sua validade no mundo jurídico. O direito de propriedade deixa de ser, então, exclusivamente um direito-garantia do proprietário e se torna um direito-garantia da sociedade.

Ressalta-se que a função social da propriedade não significa mero estabelecimento de limitações ao exercício do direito de propriedade ou limitações ao uso da propriedade, é muito mais amplo. A função social da propriedade é o conteúdo da propriedade privada que deve atender aos fins e políticas públicas na promoção do bem coletivo, que é objetivo da República.

Nesse sentido, Figueiredo (2008) destaca a função social, não como limite, mas como contorno jurídico da propriedade privada, quando alerta que não se pode confundir a estrutura conformadora do direito de propriedade com eventuais restrições de direitos dominiais, pois as normas ambientais que interferem na conformação do direito de propriedade constituem, em seu conjunto, a consubstanciação do princípio da função social da propriedade, mas esse princípio não é um conjunto de regras relativas à limitação do direito de propriedade, ele é o próprio contorno jurídico do instituto da propriedade privada.

Sobre esse aspecto, devemos ressaltar que a doutrina de Grau (1983), Derani (2002) e Figueiredo (2008) não se posiciona expressamente sobre a adoção da teoria interna ou externa dos direitos fundamentais ao tratar do conteúdo do princípio da função social da propriedade, mas é possível identificar que essa doutrina não compreende o direito à propriedade como um direito em si, não concebe no sistema um direito de propriedade sem a restrição do atendimento de sua função social, pois entende apenas determinado conteúdo, como proposto pela teoria interna. 


\section{A RESERVA LEGAL E SUA APLICAÇÃO NOS IMÓVEIS RURAIS NA AMAZÔNIA}

O princípio da função social da propriedade deve determinar a interpretação e aplicação da norma jurídica diante de regras que expressam interesses contrapostos, como ocorre no Código Florestal (BRASIL, 2012), que trouxe relevantes alterações ao sistema de proteção ambiental, inclusive com a criação de novos instrumentos de gestão.

A Lei Federal n. 12.651/2012 (BRASIL, 2012) regulamenta a proteção da vegetação, Áreas de Preservação Permanente e as Áreas de Reserva Legal; a exploração florestal, o suprimento de matéria-prima florestal, o controle da origem dos produtos florestais e o controle e prevenção dos incêndios florestais, e prevê instrumentos econômicos e financeiros, com o objetivo do desenvolvimento sustentável. São vários os instrumentos regulamentados pelo Código Florestal, como o Cadastro Ambiental Rural (CAR), Cotas de Reserva Ambiental, Área de Preservação Permanente (APP), a Reserva Legal e o Programa de Regularização Ambiental.

Em linhas gerais, o Código Florestal estabeleceu dois regimes distintos: um aplicável para os imóveis em que houve desmatamento ilegal em Área de Reserva Legal ou Área de Preservação Permanente antes de 22 de julho de 2008, nas chamadas de Áreas Rurais Consolidadas, e outro regime aplicável aos imóveis com desmatamento após essa data. As críticas mais relevantes têm sido em torno dos benefícios disponíveis para os imóveis em Área Rural Consolidada.

A Reserva Legal é um dos instrumentos mais polêmicos em virtude da peculiaridade de sua aplicação aos imóveis situados na Amazônia. O instituto passou por diversas transformações na evolução histórica do Brasil: o Decreto Federal n. 23.793/34 (BRASIL, 1934, art. 23) já trazia a previsão de restrição para o uso da terra, determinando que nenhum proprietário de terras cobertas de matas poderia abater mais de $75 \%$ da vegetação existente (três quartas partes). Porém, a restrição referia-se somente à vegetação espontânea, ou resultante do trabalho feito por conta da administração pública, ou de associações protetoras da natureza, e poderia ser afastada, a critério da autoridade florestal competente, no caso de pequenas propriedades isoladas que estivessem próximas de florestas ou situadas em zona urbana.

Posteriormente, a Lei Federal n. 4.771/65 (BRASIL, 1965), em sua redação original também não tratava da expressão Reserva Legal 
expressamente, mas em seu art. 15 determinava a proibição da exploração sob forma empírica das florestas primitivas da bacia amazônica, que só poderiam ser utilizadas em observância a planos técnicos de condução e manejo a serem estabelecidos por ato do Poder Público. Porém o artigo não chegou a ser regulamentado. $\mathrm{O}$ art. 44 trazia uma regra para ser aplicada, enquanto não houvesse a regulamentação prevista no art. 15. Estabelecia que durante este período, na região Norte e na parte Norte da região Centro-Oeste, a exploração a corte raso só seria permissível desde que permanecesse com cobertura arbórea de pelo menos $50 \%$ da área de cada propriedade.

O texto do Código Florestal de 1965 (BRASIL, 1965) foi alterado em diversas situações desde a Lei Federal n. 7.803/89 (BRASIL, 1989), que dispôs sobre a Reserva Legal de $50 \%$ para a região Norte do país. De 1996 a 2001, foram diversas as alterações por meio de Medidas Provisórias (MP) que geraram confusão legislativa e grande insegurança jurídica na aplicação do instituto.

A alteração feita pela Medida Provisória n. 1.511, de 25 de julho de 1996 (BRASIL 1996) no texto do art. 44 do Código Florestal de 1965 (BRASIL, 1965) gerou bastante impacto nas propriedades na Amazônia porque além de determinar que na região Norte e na parte norte da região Centro-Oeste, a exploração a corte raso só seria permitida desde que permanecesse com cobertura arbórea de, no mínimo, $50 \%$ de cada propriedade, mas o $\S 2^{\circ}$ do mesmo art. 44 determinava que propriedades onde a cobertura arbórea se constitui de fitofisionomias florestais, não seria mais admitido o corte raso em pelo menos $80 \%$ dessas tipologias florestais. Assim, criou dois percentuais de Reserva Legal: 50\% para as propriedades na região Norte e na parte Norte da região Centro-Oeste e $80 \%$ para as propriedades onde a cobertura arbórea se constitui de fitofisionomias florestais, nas mesmas regiões.

Em 1997, a Medida Provisória n. 1.605-18 (BRASIL, 1997, art. 44, $\S 6^{\circ}$ ) possibilitou a redução da Reserva Legal para o limite mínimo de $50 \%$ da cobertura arbórea de cada propriedade, nas áreas onde estivesse concluído o Zoneamento Ecológico-Econômico (ZEE).

A Medida Provisória n. 1.956-44 (BRASIL, 1999) foi a que apresentou maior alteração no texto da Lei Federal n. 4.771/65 (BRASIL, 1965): alterou os limites de Reserva Legal, além de fixar outras condições para a redução e ampliação da Reserva Legal pelo ZEE e para o cômputo das áreas relativas à vegetação nativa existentes em APP no cálculo do percentual de 
Reserva Legal, fixou os percentuais de Reserva Legal nos limites mínimos de: I - 80\% na propriedade rural situada em área de floresta localizada na Amazônia Legal; II - 35\% na propriedade rural situada em área de cerrado localizada na Amazônia Legal, sendo no mínimo 20\% na propriedade e $15 \%$ na forma de compensação em outra área, desde que esteja localizada na mesma microbacia.

A Medida Provisória n. 2.166-65, de 28 de junho de 2001 (BRASIL, 2001) foi a última a ser editada e manteve os índices da Medida Provisória n. 1.956-44 (BRASIL, 1999), até a edição da atual Lei Federal n. 12.651, de 2012 (BRASIL, 2012).

Assim, a regulamentação da Reserva Legal nos imóveis rurais na área de floresta da Amazônia Legal é marcada por alterações por meio de medidas provisórias sucessivas e reedições em pouco espaço de tempo, que não permitiam a adaptação da legislação e gestão local, muito menos a garantia da informação adequada aos destinatários da norma, prejudicando a eficiência do instituto.

\subsection{A Reserva Legal no Imóvel Rural na Amazônia Legal}

O conceito de Reserva Legal está disposto no art. $3^{\circ}$, III, da Lei Federal n. 12.651/2012 (BRASIL, 2012), como área localizada no interior de uma propriedade ou posse rural, delimitada nos termos especificados no artigo 12 da mesma Lei, com a função de assegurar o uso econômico de modo sustentável dos recursos naturais do imóvel rural, auxiliar a conservação e a reabilitação dos processos ecológicos e promover a conservação da biodiversidade, bem como o abrigo e a proteção de fauna silvestre e da flora nativa.

A Reserva Legal deve ser conservada com cobertura de vegetação nativa pelo proprietário, possuidor ou ocupante, a qualquer título, do imóvel rural, pessoa física ou jurídica, de direito público ou privado.

O primeiro desafio é identificar a noção de imóvel rural. Existe uma polêmica em torno da definição de imóvel rural: o Código Tributário Nacional, Lei Federal n. 5.172/66 (BRASIL, 1966, art. 32, § $1^{\circ}$ ), utiliza o critério da localização do imóvel para definição do imóvel rural, quando determina que o imposto sobre a propriedade predial e territorial urbana tem como fato gerador a propriedade, o domínio útil ou a posse de bem imóvel localizado na zona urbana do Município. Em outro sentido, o Estatuto da Terra, Lei Federal n. 4.504/64 (BRASIL, 1964, art. 4º, I), utiliza o critério 
da destinação para definição do imóvel rural, que define como prédio rústico, de área contínua qualquer que seja sua localização que se destina à exploração extrativa agrícola, pecuária ou agroindustrial, quer através de planos públicos de valorização, quer através de iniciativa privada.

Embora não haja nenhuma previsão legal específica na Lei Federal de n. 12.651/2012 (BRASIL, 2012) ou nos respectivos decretos regulamentadores da referida Lei, a Instrução Normativa n. 2, de 05 de maio de 2014, do Ministério do Meio Ambiente (BRASIL, 2014), que dispõe sobre os procedimentos para o Sistema de Cadastro Ambiental Rural (SICAR), expressamente adota o conceito de imóvel rural do Estatuto da Terra.

Admite-se a exploração econômica da Reserva Legal mediante manejo sustentável, previamente aprovado pelo órgão competente do Sistema Nacional do Meio Ambiente (SISNAMA), de acordo com a adoção de práticas de exploração seletiva nas modalidades de manejo sustentável, sem propósito comercial, para consumo na propriedade, e na modalidade de manejo sustentável para exploração florestal com propósito comercial, conforme art. 17, $\S 1^{\circ}$, e art. 20 da Lei Federal n. 12.651/2012 (BRASIL, 2012).

Aliás, esse é um esclarecimento importante porque havia muitas dúvidas sobre a utilização econômica da Reserva Legal na Amazônia. Como bem explica Lilian Haber (2015), parte da doutrina defendia a utilização da Reserva Legal com viés econômico e outros defendiam seu não uso, mas para os ruralistas, a Reserva Legal sempre se caracterizou como um impeditivo econômico, em especial na Amazônia, cujo percentual é de $80 \%$ de Reserva Legal em área de floresta, restando somente 20\% de área para o uso alternativo do solo.

O art. 12 do Código Florestal (BRASIL, 2012) determina que todo imóvel rural deve manter área com cobertura de vegetação nativa a título de Reserva Legal, sem prejuízo da aplicação das normas sobre as Áreas de Preservação Permanente, observados os percentuais mínimos em relação à área do imóvel localizado na Amazônia Legal: (a) 80\% no imóvel situado em área de floresta; (b) 35\% no imóvel situado em área de cerrado; e (c) $20 \%$ no imóvel situado em área de campos gerais, localizado nas demais regiões do país.

Embora o percentual de Reserva Legal na Amazônia seja considerado alto, o próprio texto legal elegeu várias hipóteses de alteração desse dimensionamento. $\mathrm{O}$ art. $12, \S \S 4^{\circ}$ e $5^{\circ}$, e o art. 13, I, do Código Florestal (BRASIL, 
2012) estabelecem as hipóteses de redução da área de Reserva Legal e o art. 13, II, estabelece as hipóteses de ampliação da área. Merece destaque também a redução da Reserva Legal originada da aplicação do art. 68.

Nos imóveis localizados na Amazônia Legal, o Poder Público poderá reduzir a Reserva Legal para até $50 \%$ da propriedade, para fins de recomposição, quando o Município tiver mais de $50 \%$ da área ocupada por unidades de conservação da natureza de domínio público e por terras indígenas homologadas, conforme dispõe o art. 12, § $4^{\circ}$, da Lei Federal n. 12.651/2012 (BRASIL, 2012).

O Poder Público estadual, ouvido o Conselho Estadual de Meio Ambiente, poderá reduzir a Reserva Legal da área de floresta da Amazônia Legal para até $50 \%$, quando o estado tiver ZEE aprovado e mais de $65 \%$ de seu território ocupado por unidades de conservação da natureza de domínio público, devidamente regularizadas, e por terras indígenas homologadas, exigências fixadas no art. $12, \S 5^{\circ}$, da Lei Federal n. 12.651/2012 (BRASIL, 2012).

Ressalta-se a inovação do art. 13, I, da Lei Federal n. 12.651/2012 (BRASIL, 2012), criou nova hipótese de redimensionamento de Reserva Legal. Quando indicado pelo ZEE estadual, a União pode reduzir a área de preservação para até $50 \%$ da propriedade quando situada em área de floresta localizada na Amazônia, exclusivamente para fins de regularização, mediante recomposição, regeneração ou compensação da Reserva Legal de imóveis com área rural consolidada, excluídas as áreas prioritárias para conservação da biodiversidade e dos recursos hídricos e os corredores ecológicos. Pode ainda ampliar as áreas de Reserva Legal em até 50\% dos percentuais previstos na Lei, para cumprir as metas de proteção da biodiversidade ou de redução de emissão de gases de efeito estufa.

A Lei Federal n. 12.651/2012 (BRASIL, 2012) determina ainda em seu art. $13, \S 1^{\circ}$, e $15, \S 2^{\circ}$, que, no caso de redução da Reserva Legal, o proprietário ou possuidor de imóvel rural que mantiver Reserva Legal conservada e averbada em área superior aos percentuais exigidos, poderá instituir a cota de Reserva Ambiental e a servidão ambiental sobre a área excedente.

O art. 68 do Código Florestal (BRASIL, 2012) criou uma hipótese que pode ser considerada como redução da Reserva Legal, pois possibilita que os proprietários ou possuidores de imóveis rurais que realizaram supressão de vegetação nativa, respeitando os percentuais de Reserva Legal previstos pela legislação em vigor à época em que ocorreu a supressão, fiquem 
dispensados de promover a recomposição, compensação ou regeneração para os percentuais exigidos na Lei.

Dessa forma, a aplicação da Reserva Legal nos imóveis rurais em área de floresta na Amazônia Legal pode ter dimensões variáveis, dependendo da regulamentação jurídica específica da União, dos estados e do município, como acontece com as diferentes regiões do estado do Pará.

\subsection{O Exemplo da Regulamentação da Reserva Legal no estado do Pará}

A revogada Lei Federal n. 4.771/65 (BRASIL, 1965) previa uma única hipótese de redução dos limites da Reserva Legal, no art. $16, \S 5^{\circ}$, que permitia ao Poder Executivo, se fosse indicado pelo ZEE e pelo Zoneamento Agrícola, ouvidos o Conselho Nacional de Meio Ambiente (CONAMA), o Ministério do Meio Ambiente (MMA) e o Ministério da Agricultura Pecuária e Abastecimento (MAPA), reduzir, para fins de recomposição, a Reserva Legal na Amazônia Legal, para até 50\% da propriedade. Assim, a redução da Reserva Legal, para fins de recomposição, deveria ser feita mediante a aprovação de Lei estadual do ZEE e, posteriormente, aprovação pelo CONAMA e por Decreto Federal.

A Lei Estadual n. 7.243, de 09 de janeiro de 2009 (PARÁ, 2009), dispõe sobre o ZEE da área de Influência das Rodovias BR 163 (Cuiabá - Santarém) e BR 230 (Transamazônica) no estado do Pará - Zona Oeste, determina o redimensionamento da Reserva Legal de $80 \%$ para até $50 \%$, para fins de recomposição nos imóveis rurais situados nas zonas de consolidação, aplicável somente para os imóveis rurais com passivo florestal adquirido antes de 6 de maio de 2005 (PARÁ, 2009). Esta lei foi reconhecida pelo Decreto Federal n. 7.130, de 11 de março de 2010 (BRASIL, 2010).

Ressalta-se que o redimensionamento da Reserva Legal previsto no ZEE da Zona Oeste entrou em vigor sob a vigência do Código Florestal anterior, de 1965 (BRASIL, 1965).

A Lei Estadual do Pará n. 7.398, de 16 de abril de 2010 (PARÁ, 2010), que dispõe sobre o ZEE da Zona Leste e Calha Norte do estado do Pará, também foi aprovada sob a vigência do Código Florestal de 1965 e também determinava o redimensionamento dos limites da Reserva Legal de 80\% para até $50 \%$ da propriedade na região, para fins apenas de recomposição, porque era a única possibilidade prevista. 
O revogado Código Florestal de 1965 (BRASIL, 1965) possibilitava ao Poder Executivo fazer a redução da Reserva Legal, para fins de recomposição, se fosse indicado no ZEE, que deveria ser aprovado por Lei Estadual, conforme dispunha o art. 16, $\S 5^{\circ}$. Ocorre que somente em 2013, o Governo Federal aprovou o ZEE da Zona Leste e Calha Norte do estado do Pará por meio do Decreto Federal de 24 abril de 2013 (BRASIL, 2013), com fundamento no art. 13, I, da Lei n. 12.651 de 2012 (BRASIL, 2012), que criou outra modalidade de redução, distinta daquela prevista na Lei Estadual n. 7.398/2010: autorizou a redução da área de Reserva Legal para até $50 \%$ da área de imóvel situado nas Zonas de Consolidação I, II e III, definidas na Lei Estadual n. 7.398/2010 do estado do Pará (PARÁ, 2010), com finalidade exclusiva de regularização, mediante recomposição, regeneração ou compensação, devendo ser excluídas da redução as áreas prioritárias para conservação da biodiversidade e dos recursos hídricos e os corredores ecológicos.

Sendo assim, embora a Lei estadual apenas fizesse referência à possibilidade de redimensionamento para fins de recomposição, o Decreto Federal autorizou a redução da área de Reserva Legal por finalidade exclusiva de regularização, mediante recomposição, regeneração ou compensação.

A Lei n. 12.651/2012 (BRASIL, 2012) dispõe sobre o conceito de área rural consolidada como a área de imóvel rural com ocupação antrópica preexistente a 22 de julho de 2008, com edificações, benfeitorias ou atividades agrossilvopastoris, admitida, neste último caso, a adoção do regime de pousio (art. $3^{\circ}$, IV, da Lei Federal n. 12.651/2012).

Na legislação estadual do Pará, duas leis de Zoneamento fixam marcos temporais para áreas consolidadas. A Lei Estadual n. 7.398/2010 (PARÁ, 2010) adota em seu art. $8^{\circ}, \S 3^{\circ}$, do marco temporal de 31 de dezembro de 2006. A Lei n. 7.243/2009 (PARÁ, 2009) adota em seu art. $8^{\circ}$, § $2^{\circ}$, o marco legal temporal de 06 de maio de 2005.

Caso o estado do Pará permaneça com distintos marcos temporais para áreas consolidadas definidas no Código Florestal e nas leis de zoneamento estaduais, terá que trabalhar com cenários diferentes para cada região zoneada e adaptar todo o sistema de controle e monitoramento. É possível que o estado do Pará adote o único marco temporal de 22 de julho de 2008 para definição da área consolidada, como definido na norma geral, Lei n. 12.651/2012 (BRASIL, 2012), visando à facilitação na elaboração do sistema operacional de controle e monitoramento da posse e propriedade no estado (FONSECA, 2017). 
O cenário de múltiplos limites de área de Reserva Legal na área de floresta na Amazônia contribui para inadequada aplicação do instituto e desprezo ao princípio da função social da propriedade.

\section{A RESERVA LEGAL NA AMAZÔNIA E A COMPATIBILIDADE COM FUNÇÃO SOCIAL DA PROPRIEDADE}

A Amazônia Legal atualmente, abrange todos os estados da região Norte do Brasil (Acre, Amazonas, Amapá, Pará, Rondônia, Roraima e Tocantins), toda a área de Mato Grosso e parte do estado do Maranhão, situados a oeste do meridiano $44^{\circ}$. A área da Amazônia legal é equivalente a $59 \%$ do território nacional, com extensão total de aproximadamente $5.020 .000 \mathrm{~km}^{2}$ (IBGE, 2019). É cenário de grandes conflitos socioambientais, que envolvem o combate ao desmatamento, a exploração ilegal dos recursos florestais, impactos decorrentes de grandes projetos, violência, indefinição fundiária e desprezo às normas trabalhistas.

O mapa político da Amazônia Legal contrapõe-se à lógica tradicional da divisão política do espaço, associada à repartição de competências políticas e de encargos tributários, que define a divisão entre estados e municípios. A lógica partiu da necessidade de desenvolvimento da região com demandas especiais, porém, essa região não está imune à disputa dos estoques de riquezas naturais no cenário mundial.

Até 2012, 62\% da área da Amazônia Legal era coberta por florestas, $2 \%$ pela rede hidrográfica (rios e lagos), $20 \%$ por vegetação nativa não florestal e $15 \%$ por áreas desmatadas. Entretanto, ao considerar somente o bioma Amazônia, o desmatamento atingiu 19\% da área de floresta da região. Entre 1996 e 2005, a área desmatada anualmente atingiu uma média de 19,6 mil quilômetros quadrados; entre 2006 e 2012 a área desmatada diminui para uma média de 9,2 mil quilômetros quadrados (SANTOS; PEREIRA; VERÍSSIMO, 2013).

Em setembro de 2018, foram identificados 444 quilômetros quadrados de desmatamento na Amazônia Legal, um aumento de $84 \%$ em relação a setembro de 2017, quando o desmatamento somou 241 quilômetros quadrados. [...] As florestas degradadas na Amazônia Legal somaram 138 quilômetros quadrados em setembro de 2018, apresentando uma redução de 96\% em relação a setembro de 2017, quando a degradação florestal detectada totalizou 3.479 quilômetros quadrados (FONSECA et al., 2018). 
Bertha Becker (2005) ressalta que se há uma valorização da natureza e da Amazônia, há também a relativização do poder da virtualidade dos fluxos e redes do mundo contemporâneo. A globalização atenua as percepções de fronteiras e Estados, o que acompanha uma disputa das potências pelos estoques das riquezas naturais, mas devemos considerar a desigual distribuição geográfica de tecnologia e de recursos, já que as tecnologias avançadas são desenvolvidas nos centros de poder e as reservas naturais estão localizadas nos países periféricos ou em áreas não regulamentadas juridicamente.

O exercício da propriedade privada e a função social do imóvel rural na área de floresta da Amazônia Legal devem ser compreendidos nesse cenário de tensão entre a necessidade de produção de riqueza, por meio da exploração dos recursos naturais e a necessidade de conservação da biodiversidade e dos recursos naturais.

O histórico de ocupação da Amazônia é marcado pela concentração de terras por grupos privilegiados e aumento da desigualdade. Loureiro (2004) ressalta que a análise da história, antiga ou recente da Amazônia e do Brasil permite constatar que o Estado brasileiro vem transferindo secularmente os bens da natureza a grupos e classes sociais privilegiados, em prejuízo dos demais.

Além da preservação da biodiversidade, um outro desafio na Amazônia está relacionado à titularidade da terra. Não é apenas a propriedade que deve cumprir sua função social, mas também a posse (MOREIRA; FONSECA, 2009). O uso da terra na Amazônia deve atender a sua função social e a obrigação relacionada à Reserva Legal é atribuída ao imóvel, independente de quem esteja no exercício da posse ou propriedade.

Como já alertado, a função social da propriedade não significa mero estabelecimento de limitações ao exercício do direito de propriedade. É necessário identificar o conteúdo econômico, ambiental e social do imóvel rural para identificar a função social da propriedade, e a Reserva Legal é um dos instrumentos legais que concorre para garantir da condição ambiental do imóvel rural.

É evidente que a Reserva Legal implica restrição do uso da propriedade privada, porém ao mesmo tempo implica condição de sustentabilidade de exploração do próprio imóvel rural, que somente poderá ser utilizada por meio da aprovação de Plano De Manejo Florestal Sustentável (PMFS), que contemple técnicas de condução, exploração, reposição florestal e manejo compatíveis com os variados ecossistemas, conforme o dispõe o art. 31 da Lei Federal 12.651/2012 (BRASIL, 2012). 
O plano de manejo florestal sustentável é essencial para garantir a compatibilidade entre o aspecto econômico e o ambiental da função social do imóvel rural na área de floresta na Amazônia. Esse é, certamente, o grande desafio relacionado à análise da função social da propriedade: parte do imóvel rural é considerado Área de Uso Alternativo do Solo (AUAS) e pode ser utilizado para exploração sem restrições específicas, e parte do imóvel somente poderá ser utilizada por meio da aprovação do plano de manejo florestal sustentável pelo órgão ambiental competente.

Ocorre que o percentual de área de uso alternativo do solo e de Reserva Legal de cada imóvel rural na Amazônia vai depender da regulamentação específica de cada região. No Pará, como exemplo já demonstrado, há imóveis rurais em áreas de floresta, localizados em áreas rurais consolidadas, cuja área de Reserva Legal é de 80 a 50\% para fins de recomposição (áreas inseridas no ZEE da Zona Oeste); e há imóveis rurais localizados em áreas de floresta em áreas rurais consolidadas, cuja área de Reserva Legal é de 80 a 50\% para fins de regularização, permitindo a recomposição, regeneração e compensação; e há ainda os imóveis rurais que não estão inseridos em áreas rurais consolidadas, com Reserva Legal de $80 \%$, inclusive para fins de recomposição.

Sendo assim, a Reserva Legal é determinante para análise do aspecto ambiental da função social da propriedade do imóvel rural na área de floresta na Amazônia Legal e para toda a complexidade de identificação do percentual de Reserva Legal, assim como para as formas de regularização do imóvel, por meio de recomposição, regeneração ou compensação, que passam a compor também os desafios da identificação do cumprimento da função social da propriedade.

Assim, se por um lado a função social da propriedade é o fundamento jurídico para a criação do instituto da Reserva Legal; por outro lado a Reserva Legal passa ser uma das condições de cumprimento do aspecto ambiental da função social da propriedade. Isto não quer dizer que a Reserva Legal seja o próprio aspecto ambiental da função social da propriedade.

Como já destacado, a função social é o próprio contorno jurídico da propriedade privada, e não se pode confundir a estrutura conformadora do direito de propriedade com eventuais restrições de direitos dominiais, pois as normas ambientais que interferem na conformação do direito de propriedade constituem, em seu conjunto, a consubstanciação do princípio da função social da propriedade, mas não é esse princípio um conjunto de regras relativas à limitação do direito de propriedade, ele é o próprio 
contorno jurídico do instituto da propriedade privada (FIGUEIREDO, 2008).

A exigência de cumprimento da Reserva Legal pelo proprietário do imóvel rural é um direito subjetivo atribuído ao Estado e à coletividade, a fim de que a relação de propriedade se mantenha válida.

\section{CONCLUSÃO}

Com base na noção de propriedade privada e função social da propriedade como direitos fundamentais e princípios da ordem econômica, o artigo partiu para uma análise mais específica, considerando o direito de propriedade uma relação entre um indivíduo e um objeto, que também indica uma oposição entre o sujeito dessa relação e a universalidade de sujeitos. Conclui-se, assim, que o direito de propriedade é uma relação de um sujeito sobre um objeto, protegida pelo Direito, desde que preencha requisitos e condições fixadas por este.

A função social da propriedade é um ônus do proprietário privado perante a sociedade, recaindo sobre o desenvolvimento da relação de poder entre sujeito e objeto, que configura propriedade. O ônus significa que sua atuação deve trazer um resultado vantajoso para a sociedade para que exista a proteção do direito sobre a propriedade.

Os critérios de cumprimento da função social do imóvel rural merecem destaque: o critério do uso racional da terra da terra constitui o aspecto econômico; a utilização adequada dos recursos naturais disponíveis e a preservação do meio ambiente constituem o aspecto ambiental; e a observância das disposições que regulam as relações de trabalho e a exploração que favoreça o bem-estar dos proprietários e dos trabalhadores constituem o aspecto social (BRASIL, 1988, art. 186, I, II e III da Constituição). Dispostos no texto constitucional, tais critérios necessitam de regulamentação jurídica infraconstitucional para serem aplicados.

Com relação ao critério ambiental, deve-se observar a vasta legislação infraconstitucional, como o Código Florestal, Lei Federal n. 12.651/2012 (BRASIL, 2012), que regulamenta institutos como a Reserva Legal, um dos mais polêmicos e de grande impacto para os imóveis rurais na Amazônia.

A evolução da regulamentação jurídica da Reserva Legal é marcada por alterações advindas de medidas provisórias sucessivas e reedições em pouco tempo, o que não permitia a adaptação da legislação e da gestão local, muito menos a garantia da informação adequada aos destinatários da norma, prejudicando a eficiência do instituto. 